\title{
IDENTIFICAÇÃO E ANÁLISE DE MANIFESTAÇÕES PATOLÓGICAS INCIDENTES NO ESTACIONAMENTO SUPERIOR DE UM SHOPPING CENTER: LEVANTAMENTO DE POSSÍVEIS CAUSAS E PROPOSTA DE INTERVENÇÃO
}

\author{
CALHEIROS SOARES, RICARDO \\ Docente - Engenharia Civil \\ Instituto Federal de Alagoas \\ Alagoas; Brasil \\ ricardo.soares@ifal.edu.br
}

\author{
SAMUEL DE OLIVEIRA JÚNIOR, JORGE \\ Discente - Engenharia Civil \\ Instituto Federal de Alagoas \\ Alagoas; Brasil \\ jorge.samuel.jo@gmail.com
}

\section{RESUMO}

Patologia das construções é o nome dado à área da engenharia que estuda os defeitos ou problemas que surgem nas construções (Fonseca et al, 2015). Esses problemas podem ser originados por erro de projeto ou execução; má escolha dos materiais empregados na obra ou má utilização. O presente estudo foi feito exclusivamente na parte superior de um estacionamento, onde foi observada uma oportunidade de avaliação com um foco definido - avaliação esta que constata problemas típicos decorrentes do fluxo de usuários combinado com ausência de manutenção periódica. Para a concepção deste estudo, foi realizada uma revisão bibliográfica e, posteriormente, visitas in loco, onde foram observadas as patologias e estudadas as suas causas, sendo elaborada uma representação técnica que demostra os resultados da avaliação, incluindo gráficos com incidências e fotos que identificam riscos de acidente e necessidade de manutenção.

Palavras-chave: Engenharia Civil, Laje, Patologia das Construções.

\section{ABSTRACT}

Construction Pathology is the name given to the engineering area that studies the defects or problems that appear in buildings (Fonseca et al, 2015). These problems can be caused by design or execution error; poor choice of materials used on site or misuse. The present study was conducted exclusively at the top of the parking lot, where a focused focus assessment opportunity was observed - one that shows typical problems arising from the flow of users combined with the absence of periodic maintenance. For the conception of this study, a bibliographic review was carried out and, later, on-site visits, where the pathologies and their causes were observed, and a technical representation was elaborated that shows the evaluation results, including incidence graphs and photos that identify risks of accidents and need for maintenance.

Keywords: Civil Engineering, Slab, Pathology.

\section{INTRODUÇÃO}

Os diversos setores da atividade humana estão atrelados à construção civil. Seja para fins comerciais, culturais ou residenciais, o homem necessita de edificações pelos mais diferentes motivos. Eventualmente, seja por erro de projeto, execução, manutenção ou uso, as edificações apresentam problemas e falhas. Os problemas incidentes em edificações são chamados de manifestações patológicas e área da ciência os aborda e compreende é a de patologia na construção civil.

A Patologia na construção civil é a área que estuda os sintomas, causas, origens e tratamentos dos problemas encontrados em edificações, segundo Do Carmo (2003, apud ZUCHETTI, 2015). Uma vez que é crescente a conscientização por parte dos clientes sobre a qualidade das construções adquiridas, como apontado por Macedo (2017), é maior a exigência e a necessidade de acompanhar a qualidade da obra após a entrega de chaves.

Além de apresentar possíveis riscos à segurança, a incidência de manifestações patológicas vai de encontro aos padrões exigidos das edificações por parte da NBR 15575:2013, a norma que rege o desempenho das edificações, apresentando as condições mínimas que ela deve proporcionar durante sua vida-útil. 
Em outubro de 2019 foi feito um levantamento de manifestações patológicas incidentes no estacionamento superior de um shopping center presente na região agreste para fins de conhecimento e contribuição científica.

O presente artigo visa ilustrar as possíveis causas dos problemas encontrados no estacionamento, seus métodos preventivos e seus tratamentos. Para o levantamento foram realizadas visitas in loco e para a prescrição de tratamentos e levantamento de causas e prevenções foi utilizada uma profunda pesquisa bibliográfica.

O estacionamento foi construído sobre uma laje em concreto armado de cerca de $30000 \mathrm{~m}^{2}$, sobre a laje foi construído um piso em placas cimentadas com juntas de dilatação entre as placas. Há pequenas construções sobre a laje, como, por exemplo, os muros que delimitam o estacionamento e salas de manutenção. Os muros e paredes das salas são construídos em alvenaria de blocos cerâmicos e seu revestimento é argamassado com aplicação de tinta na superfície. No topo das salas de manutenção estão presentes vigas de periferia e uma laje em concreto armado.

Levando em consideração o escopo da obra, identifica-se que se aplicam a ela as prescrições normativas da NBR 15575-1:2013 - Requisitos gerais, NBR 15575-2:2013 - Requisitos para os sistemas estruturais, NBR 15575-3:2013 Requisitos para os sistemas de pisos, NBR 15575-4:2013 - Requisitos para os sistemas de vedações verticais internas e externas e a NBR 15575-5:2013 - Requisitos para os sistemas de coberturas.

\section{OBJETIVOS}

O presente trabalho possui, como objetivo geral, expôr os problemas encontrados no estacionamento superior de shopping center localizado na região agreste, assim como suas causas e possíveis tratamentos.

Como objetivos específicos, os autores do trabalho visam:

a. Identificar graus de risco das manifestações patológicas encontradas;

b. Atribuir as causas identificadas a erros de projeto, execução, utilização ou manutenção

c. Comparar os problemas identificados com as prescrições normativas da NBR 15575:2013.

\section{METODOLOGIA}

Foi definida uma metologia de trabalho para o levantamento e estudo das manifestações patológicas: foi realizada uma visita ao local, portando uma máquina para registros fotográficos, e foram capturados todos os problemas evidenciados no estacionamento; após isso, tendo conhecimento de todos os problemas, a bibliografia a respeito do tema foi buscada, onde causas e soluções foram estudadas para a produção desse material.

Para apresentar os dados, foram utilizadas imagens do local, unidas a gráfico e tabela para mais clareza.

\section{RESULTADOS}

Quanto às manifestações patológicas encontradas no estacionamento, elas foram, significantemente, causadas por erros de utilização e manutenção e por adaptações e extensões não previstas em projeto.

\subsection{Manifestações patológicas em alvenarias, estruturas verticais e revestimentos}

A Figura 1 exibe um desplacamento da textura aplicada em um trecho de alvenenaria. Trata-se de um erro de execução. Iliescu (2007, apud DE MILITO, 2009), em seu trabalho, trata dos principais tipos de problemas encontrados em pinturas e revestimentos. Segundo o material do autor, uma possível causa para o desplacamento da textura é a umidade presente no revestimento argamassado quando a textura foi aplicada. Há uma cura necessária de 30 dias antes da aplicação do material. Uma outra possível causa é que o material tenha sido diluído de maneira inadequada, afetando sua aderência. 


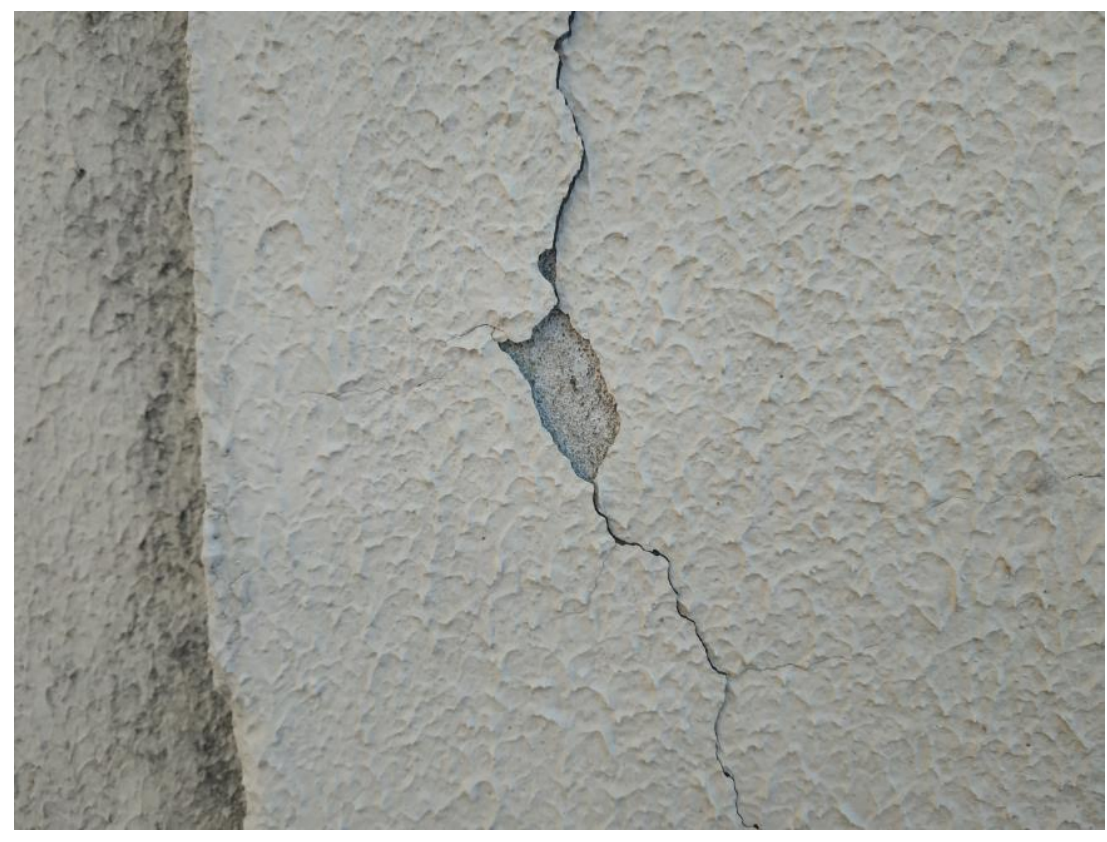

Figura 1: Desplacamento de textura

Um tratamento sugerido é a renovação da textura, sendo aplicada novamente com a superfície, suficientemente, seca.

Segundo a definição de Gonçalves (2015) para elementos estruturais, fissuras podem ser entendidas como aberturas incidentes na superfície de elementos construtivos que permitem a entrada de agentes externos. A NBR 6118:2014 delimita a abertura máxima de fissuras em elementos estruturais, a depender da classe de agressividade do meio e do elemento. Segundo Souza e Ripper (1998, apud MACEDO, 2017), é o tipo de manifestação mais comum e que mais captura a atenção dos usuários das edificações.

Na Figura 2 pode ser visto um problema de fissuração.

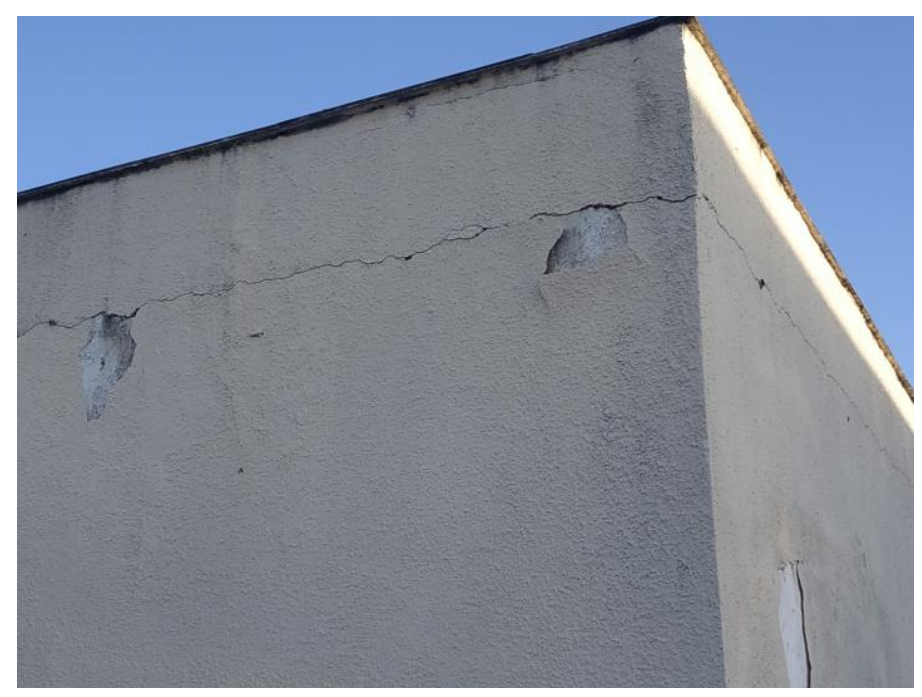

Figura 2: Fissuração entre alvenaria e estrutura

Trata-se de um erro referente aos materiais implementados. A Figura evidencia que a fissura ocorre no encontro entre uma viga e a alvenaria de vedação. Uma possível causa da fissura é a diferença dos coeficientes de dilatação do concreto e da alvenaria. Segundo Verçosa (1991, apud MAGALHÃES, 2004), o coeficiente de dilatação do concreto é cerca do dobro do coeficiente de dilatação da alvenaria. Esse tipo de fissuração é identificado no trabalho de Magalhães 
(2004): esse tipo de fissura é tipicamente horizontal e acontece na fronteira entre a laje e a alvenaria ou um pouco mais abaixo paralelo à laje. Ocorre devido a variação dimensional da laje que provoca tensões de cisalhamento na alvenaria.

Para controlar a movimentação térmica das lajes, deve-se controlar a incidência de calor sobre elas, utilizando algum dispositivo de sombreamento, como um telhado, segundo Resende, et al (2018). Outra opção é a utilização de juntas elásticas no encontro entre alvenaria e estrutura, como sugerido por Silva (2002, apud RESENDE, ET AL, 2018) e exibido na Figura 3.

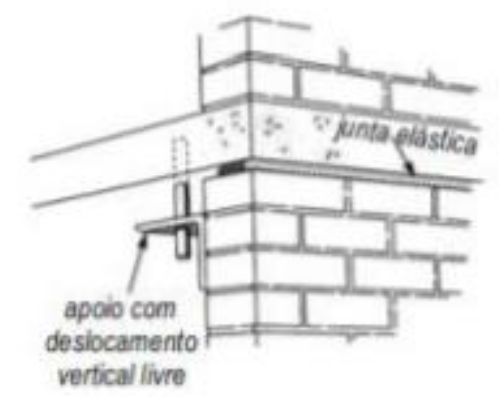

Figura 3: Junta elástica no encontro entre alvenaria e estrutura (Resende, Martins e Freitas. 2018)

Como forma de tratamento, pode-se aplicar telas metálicas superficialmente no encontro entre alvenaria e estrutura, como sugerido por Resende, et al (2018) e exibido na Figura 4. No caso da edificação analisada, o revestimento argamassado deveria ser removido para a aplicação da tela e, em seguida, renovado.

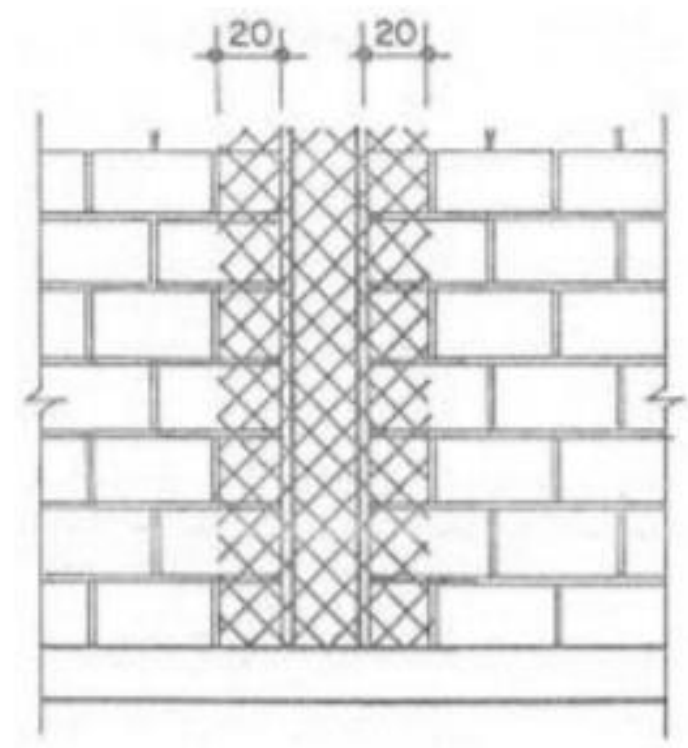

Figura 4: Encontro entre alvenaria e estrutura coberto com tela metálica (Resende, Martins e Freitas. 2018)

A Figura 5 exibe um problema de desagregação do revestimento argamassado. Trata-se de um erro de execução. Sob o revestimento está presente um trecho de manta asfáltica aplicada. Uma possível causa identificada para o problema é um furo presente na manta que proporcionou a percolação da água e, por sua vez, a umidade foi capaz de desagregar o reboco. 


\section{CBPAT 2020 \\ CONGRESSO BRASILEIRO DE PATOLOGIA DAS CONSTRUÇÕES \\ DE 15 A 17 DE ABRIL | FORTALEZA - CE}

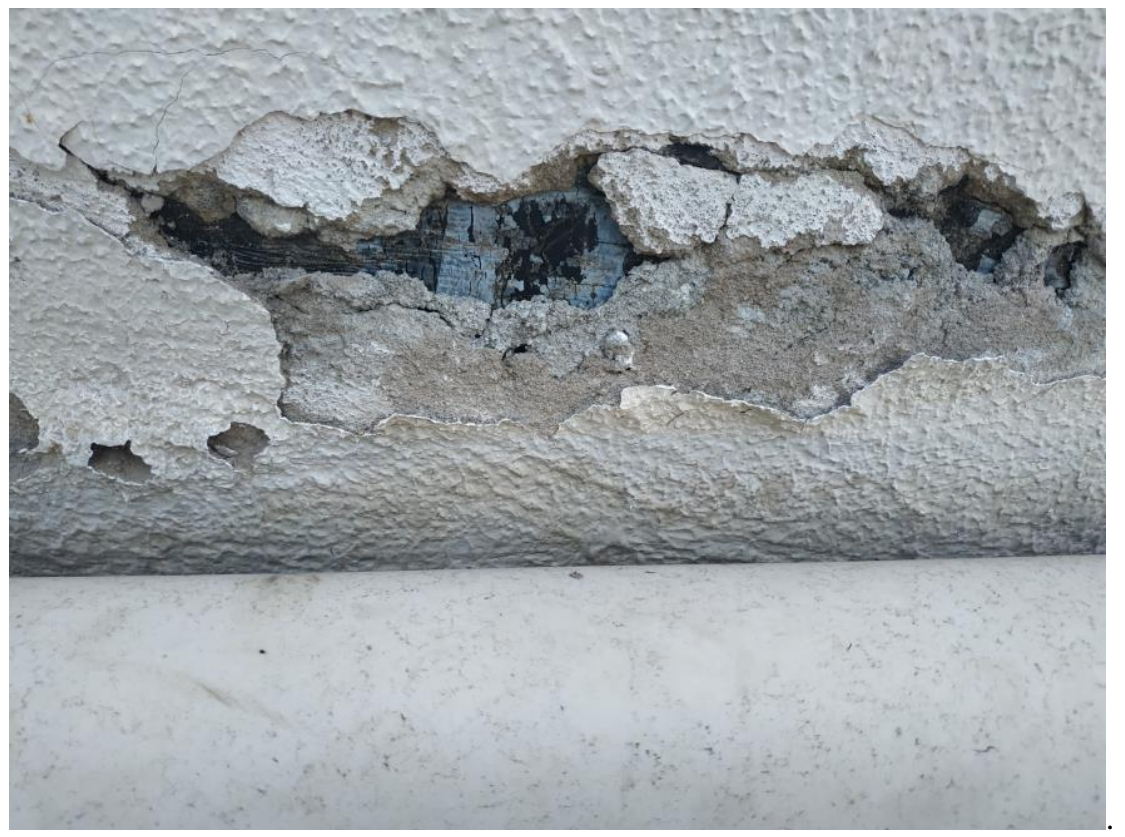

Figura 5: Reboco de parede desagregado devido a umidade

De Milito (2009) afirma, analogamente, que a presença de umidade contínua em paredes pode, além de provocar bolhas abaixo da pintura, causando o desplacamento do revestimento argamassado. Para o problema identificado, o tratamento sugerido é executar os reparos necessários no dispositivo de impermeabilização e renovar o revestimento e pintura.

A Figura 6 ilustra um problema de desplacamento e, possivelmente, carbonatação encontrado em um pilar. Trata-se de um problema de projeto e/ou execução.

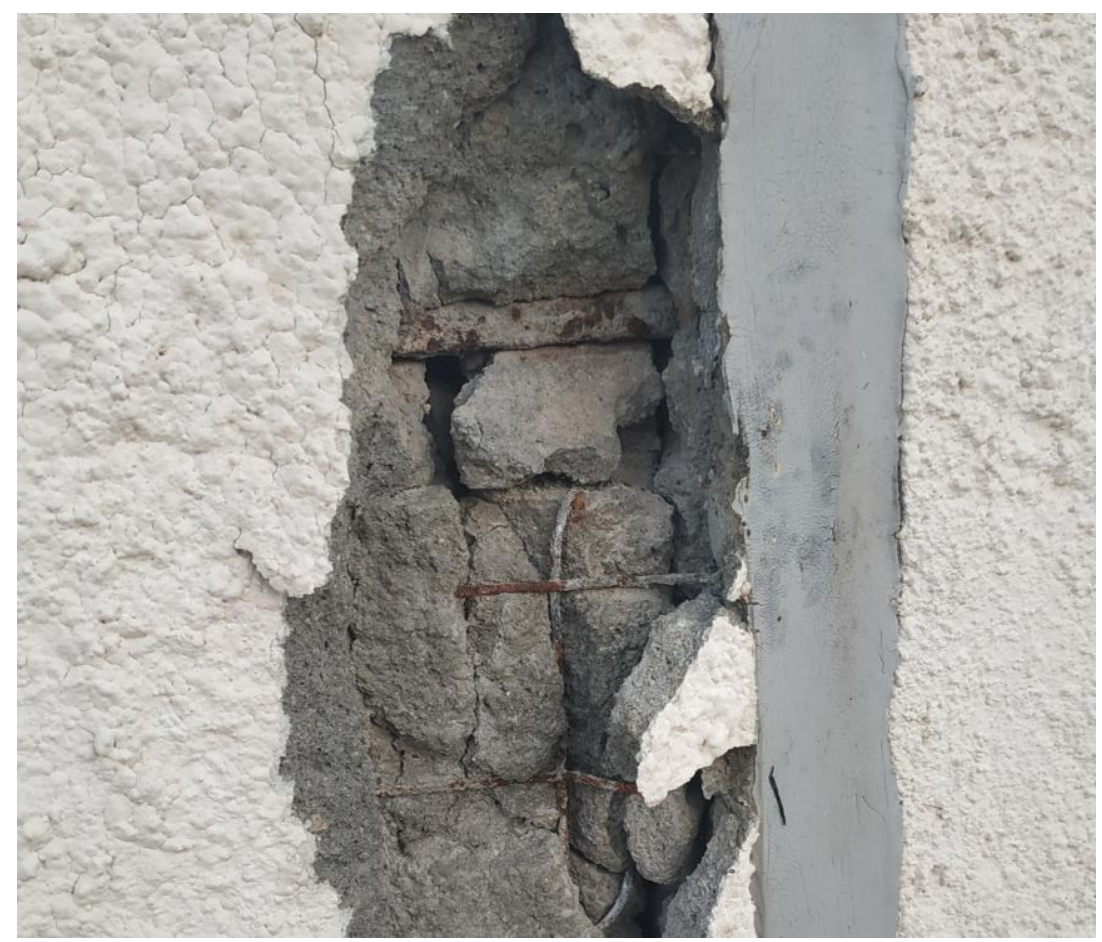

Figura 6: Possível carbonatação em estrutura de pilar 
Parte dos gases que levam à carbonatação estão no ar atmosférico, segundo Pires (2016). A carbonatação, por causar a oxidação e o aumento da seção do concreto, pode acabar por causar desplacamento do concreto. A NBR 6118:2014 prevê um fck e um cobrimento mínimo de concreto para a proteção do aço. Para obter a espessura carbonatada, normalmente, utilizasse compostos à base de fnolftaleína, segundo Pires (2016). O concreto presente na estrutura possui cerca de $1 \mathrm{~cm}$ de cobrimento, sendo insuficiente perante parâmetros normativos, podendo configurar um erro de execução ou de projeto. Apesar do provável processo de carbonatação do aço, são necessários ensaios em campo para comprovar a espessura carbonatada.

Para o tratamento do problema, caso não haja perda de seção no aço, Zucchi (2015) sugere o lixamento da superfície corroída do aço, seguida a aplicação de uma camada de primer epóxi com zinco. Em seguida, a superfície desplaca do concreto deve ser preenchida com um concreto, preferencialmente, de alto desempenho. Para garantir a aderência entre o concreto novo e velho, a superfície deve ser lavada e pode ser utilizado material estrutural adesivo no encontro, segundo o autor.

Caso seja identificada perda de seção no aço, pode ser necessária a execução de reforço estrutural. Como possível sugestão para reforço em concreto armado, Zucchi (2015) aponta o encamisamento do elemento, ou seja, aliviar as cargas incidentes nele através de escoras, e envolver a seção existente com a armadura necessária e concreto de alto desempenho.

\subsection{Manifestações patológicas em pisos}

A Figura 7 ilustra uma fissura encontrada no piso do estacionamento.

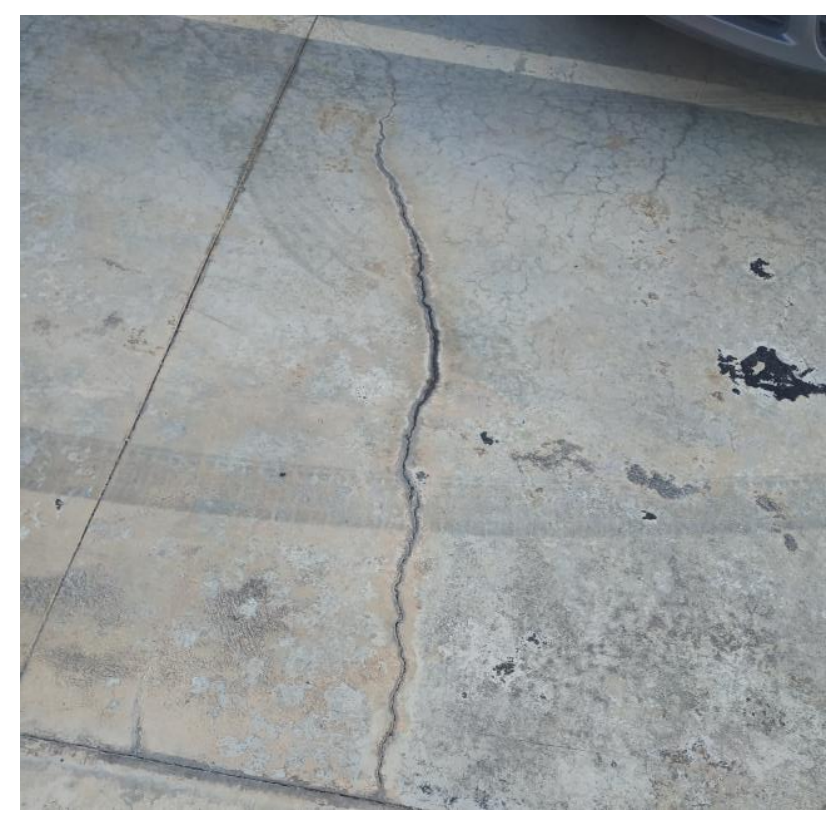

Figura 7: Fissura encontrada em piso cimentado

O piso aparenta sofrer com esforços de tração excessivos, devido a dilatação térmica aliado a sobrecargas. Possivelmente um erro de execução ou da escolha dos materiais utilizados. Para a recuperação da fissura, Vieira (2017) sugere o tratamento da fissura utilizando selagem epóxi, uma vez que a laje é feita em concreto armado e há a possibilidade da ação de cloretos.

A Figura 8 ilustra um exemplo de desgaste no piso. A provável causa do problema é a presença de agentes químicos lançados sobre o piso. 


\section{CBPAT 2020

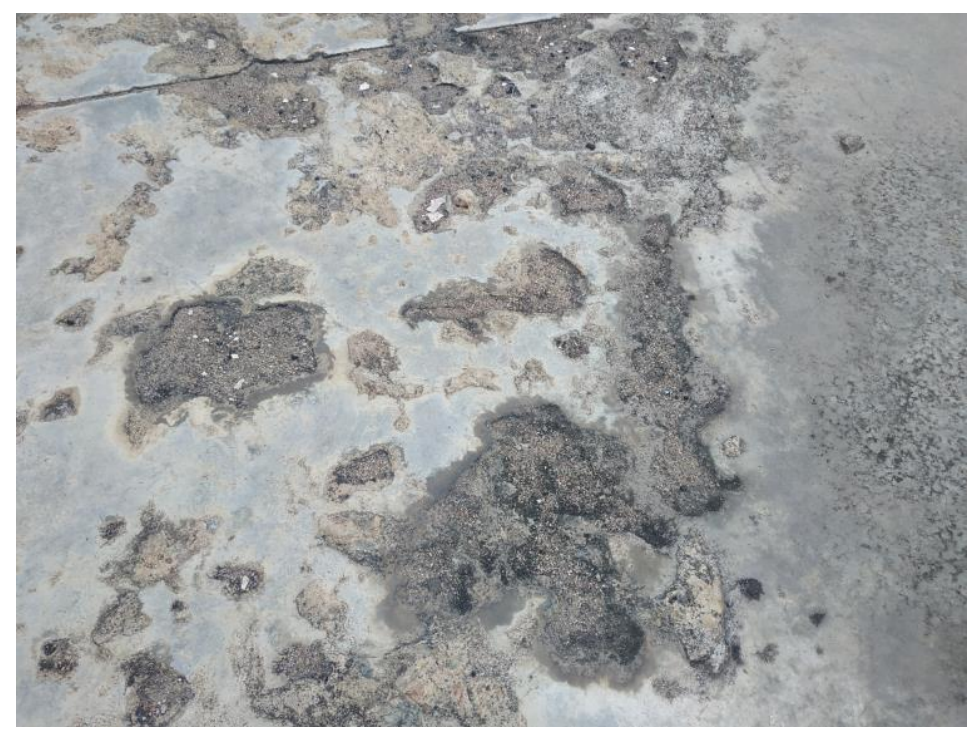

Figura 8: Desgaste em piso de concreto

Para tratar o problema, pode-se utilizar o procedimento de recuperação estrutural sugerido por Zucchi (2015) de tratar a armadura com pintura epóxi e renovar o concreto com um novo concreto de alto desempenho. Trata-se de um erro de utilização ou de escolha dos materiais implementados.

A Figura 9 ilustra um problema de desplacamento de concreto com exposição da armadura. Por se encontrar na união entre duas placas de concreto, é possível identificar que a causa foi a insuficiência de juntas de dilatação seguido da aplicação de sobrecarga por parte dos veículos no concreto fragilizado. Como explicado por Vieira (2015), não só a ausência, mas a insufiência das juntas pode acarretar em fissuras. Devido à variação dimensional, o concreto tende a quebrar no encontro entre placas. O concreto deve passar por um procedimento de reforço estrutural e tratamento da armadura para impedir a corrosão.

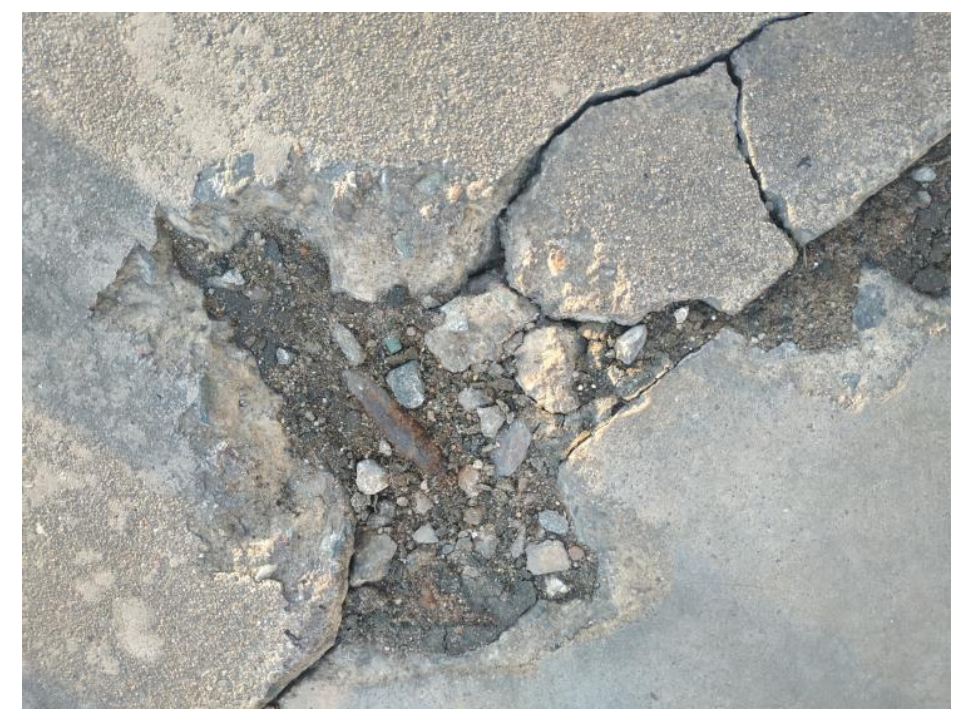

Figura 9: Desplacamento de concreto com exposição da armadura

Na Tabela 1, para fins didáticos, foram listadas as manifestações patológicas encontradas, suas possíveis causas, tratamentos e métodos preventivos. 
Tabela 1: Causas, tratamentos e prevenção das manifestações patológicas encontradas

\begin{tabular}{|c|c|c|c|c|}
\hline $\begin{array}{l}\text { Manifestação } \\
\text { patológica }\end{array}$ & Possíveis causas & Intervenção cabível & Método preventivo & Fontes utilizadas \\
\hline $\begin{array}{l}\text { Desplacamento de } \\
\text { textura e pintura }\end{array}$ & $\begin{array}{l}\text { - Não foi respeitado } \\
\text { o tempo mínimo de } \\
30 \text { dias para a } \\
\text { aplicação. } \\
\text { - Material diluído de } \\
\text { maneira inadequada. }\end{array}$ & $\begin{array}{l}\text { - Remoção e } \\
\text { renovação do } \\
\text { acabamento. }\end{array}$ & $\begin{array}{l}\text { - Aguardar, no } \\
\text { mínimo, } 30 \text { dias após } \\
\text { a aplicação do } \\
\text { revestimento } \\
\text { argamassado para a } \\
\text { aplicação da textura } \\
\text { ou pintura. } \\
\text { - Diluir o material } \\
\text { segundo as } \\
\text { instruções do } \\
\text { fabricante. }\end{array}$ & $\begin{array}{l}\text { - Iliescu (2007, apud } \\
\text { DE MILITO, 2009) }\end{array}$ \\
\hline $\begin{array}{l}\text { Fissura horizontal no } \\
\text { encontro entre } \\
\text { alvenaria e laje }\end{array}$ & $\begin{array}{l}\text { - Diferença entre os } \\
\text { coeficientes de } \\
\text { dilatação da } \\
\text { alvenaria e do } \\
\text { concreto e } \\
\text { insuficiência de } \\
\text { juntas de dilatação. }\end{array}$ & $\begin{array}{l}\text { - Remoção do } \\
\text { revestimento } \\
\text { argamassado, } \\
\text { aplicação de tela } \\
\text { metálica na união } \\
\text { entre concreto e } \\
\text { alvenaria e posterior } \\
\text { renovação do } \\
\text { revestimento. }\end{array}$ & $\begin{array}{l}\text { - Preencher a união } \\
\text { entre a alvenaria e o } \\
\text { concreto com } \\
\text { material elástico. }\end{array}$ & $\begin{array}{l}\text { - Resende, et al } \\
(2018) . \\
\text { - Verçosa (1991, } \\
\text { apud } \\
\text { MAGALHÃES, } \\
\text { 2004) }\end{array}$ \\
\hline $\begin{array}{l}\text { Desagregação de } \\
\text { revestimento } \\
\text { argamassado }\end{array}$ & $\begin{array}{l}\text { - Falha na } \\
\text { impermeabilização e } \\
\text { presença contínua de } \\
\text { umidade. }\end{array}$ & $\begin{array}{l}\text { - Reparo na } \\
\text { impermeabilização } \\
\text { falha e renovação do } \\
\text { revestimento. }\end{array}$ & $\begin{array}{l}\text { - Obedecer o } \\
\text { procedimento técnico } \\
\text { de aplicação de } \\
\text { manta } \\
\text { impermeabilizante } \\
\text { para evitar a presença } \\
\text { de umidade. } \\
\end{array}$ & - De Milito (2009) \\
\hline $\begin{array}{l}\text { Carbonatação } \\
\text { incidente em pilar }\end{array}$ & $\begin{array}{l}\text { - Não foi respeitado } \\
\text { o cobrimento } \\
\text { nominal mínimo } \\
\text { sugerido em norma. } \\
\text { - Concreto poroso. }\end{array}$ & $\begin{array}{l}\text { - Proteção da } \\
\text { armação com primer } \\
\text { específico e reparo } \\
\text { do concreto antigo } \\
\text { com concreto novo } \\
\text { de alto desempenho } \\
\text { aliado a algum } \\
\text { adesivo estrutural. } \\
\text { - Encamisamento do } \\
\text { elemento, caso haja } \\
\text { perda de seção e } \\
\text { comprometimento do } \\
\text { desempenho da } \\
\text { armadura. }\end{array}$ & $\begin{array}{l}\text { - Respeitar o } \\
\text { cobrimento nominal } \\
\text { mínimo estabelecido } \\
\text { pela NBR } \\
\text { 6118:2014. } \\
\text { - Utilizar } \\
\text { espaçadores de } \\
\text { madeira adequada ao } \\
\text { concretar o elemento. } \\
\text { - Utilizar um traço } \\
\text { adequado ao produzir } \\
\text { o concreto. }\end{array}$ & $\begin{array}{l}\text { - Pires (2016) } \\
\text { - Zucchi (2015) } \\
\text { - NBR 6118:2014 }\end{array}$ \\
\hline $\begin{array}{l}\text { Fissura em piso } \\
\text { cimentado }\end{array}$ & $\begin{array}{l}\text { - Insuficiência de } \\
\text { juntas de dilatação no } \\
\text { piso. }\end{array}$ & $\begin{array}{l}\text { - Substituição da } \\
\text { placa do piso } \\
\text { cimentado e abertura } \\
\text { das juntas na } \\
\text { espessura adequada. }\end{array}$ & $\begin{array}{l}\text { - Executar as juntas } \\
\text { de dilatação com o } \\
\text { espaçamento } \\
\text { adequado e utilizar } \\
\text { dispositivos de } \\
\text { sombreamento } \\
\text { quando possível. }\end{array}$ & - Vieira (2017) \\
\hline $\begin{array}{l}\text { Desgaste em piso } \\
\text { cimentado }\end{array}$ & $\begin{array}{l}\text { - Contato de agentes } \\
\text { químicos com o piso. }\end{array}$ & $\begin{array}{l}\text { - Remoção e } \\
\text { renovação da placa }\end{array}$ & $\begin{array}{l}\text { - Evitar o lançamento } \\
\text { de materiais }\end{array}$ & - Zucchi (2015) \\
\hline
\end{tabular}




\begin{tabular}{|c|c|c|c|c|}
\hline & & do piso cimentado. & $\begin{array}{l}\text { químicos } \\
\text { possivelmente } \\
\text { agressivos no piso. }\end{array}$ & \\
\hline $\begin{array}{l}\text { Desplacamento de } \\
\text { concreto com } \\
\text { armadura exposta }\end{array}$ & $\begin{array}{l}\text { - Insuficiência de } \\
\text { juntas de dilatação. }\end{array}$ & $\begin{array}{l}\text { - Proteção da } \\
\text { armação com primer } \\
\text { específico e reparo } \\
\text { do concreto antigo } \\
\text { com concreto novo } \\
\text { de alto desempenho } \\
\text { aliado a algum } \\
\text { adesivo estrutural. }\end{array}$ & $\begin{array}{l}\text { - Executar as juntas } \\
\text { de dilatação com o } \\
\text { espaçamento } \\
\text { adequado e utilizar } \\
\text { dispositivos de } \\
\text { sombreamento } \\
\text { quando possível. }\end{array}$ & - Zucchi (2015) \\
\hline
\end{tabular}

\section{RELAÇÃO DOS PROBLEMAS ENCONTRADOS COM AS NORMAS DE DESEMPENHO}

Identifica-se com os problemas decorrentes de umidade, como carbonatação e desplacamento de revestimento, por exemplo. Que as prescrições normativas da NBR 15575-1:2013 a respeito da estanqueidade não foram cumpridas adequadamente, uma vez que a presença de água foi responsável por parte dos problemas.

Ainda sobre a NBR 15575-1:2013, não são cumpridos os parâmetros estabelecidos para sombreamento nas lajes das salas de manutenção. A vida útil de projeto, segundo a norma, das estruturas é de 50 anos e de coberturas é de 20 anos, no mínimo.

\section{CONCLUSÃO}

Na Figura 10 elaborada pelo Autor (2019), observa-se um gráfico onde são atribuídas as fases que possivelmente ocasionaram cada lesão identificada na obra.

\section{Fase causadora de lesões}

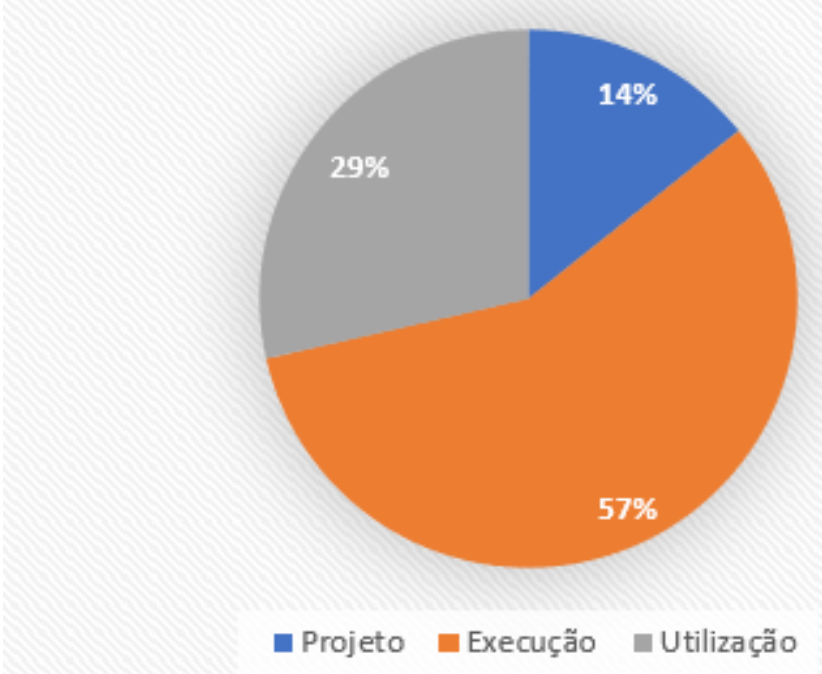

Figura 10: Fase causadora, em porcentagem, dos problemas encontrados na edificação

Com base na Figura 10 e nos dados apresentados, identifica-se que a maior parte dos problemas encontrados foram causados na fase de execução. Ou seja, a maior partes dos problemas foram originados de definições de obra não planejadas, como a ausência de junta elástica entre concreto e alvenaria ou o espaçamento e pronfudidade atribuídos às juntas de dilatação executadas no piso de concreto.

Uma vez análisados os aspectos da construção, verifica-se que a atual fase das lesões encontradas não apresenta grave risco para quem utiliza a edificação. Porém, podem violar a aceitabilidade sensorial e podem ser facilmente notadas 
pelos usuários. Porém, apesar de não apresentarem riscos atualmente, os problemas estruturais podem escalar ao longo do tempo, tornando-se um risco significativo. Apesar de o estado não ser de emergência, a edificação necessita de significativos reparos e trabalhos de manutenção.

Destaca-se que as informações presentes no trabalho foram obtidas com base no observado em campo e na literatura existente sobre o tema. Para futuros trabalhos, podem ser realizados ensaios, em laboratório ou em campo, para que sejam obtidas conclusões mais precisas, a exemplo da utilização da fnolftaleína para a obtenção da espessura carbonatada.

\section{REFERÊNCIAS}

ASSOCIAÇÃO BRASILEIRA DE NORMAS TÉCNICAS. NBR 15575-1: Edificações habitacionais - Desempenho - Parte 1: Requisitos gerais. Rio de Janeiro, 2013.

ASSOCIAÇÃO BRASILEIRA DE NORMAS TÉCNICAS. NBR 6118: Projeto de estruturas de concreto procedimento. Rio de Janeiro, 2014.

DE MILITO, J. A. Técnicas de Construção Civil. Apostila. Faculdade de Engenharia de Sorocaba. Sorocaba, SP, Brasil. 2009.

GONÇALVES, E. A. B. Estudo de patologias e suas causas nas estruturas de concreto armado de obras de edificações. Trabalho de Conclusão de Curso (Graduação) - Universidade Federal do Rio de Janeiro, Escola Politécnica. Rio de Janeiro, RJ, Brasil. 2015.

MACEDO, E. A. V. B. Patologias em obras recentes de construção civil: Análise crítica das causas e consequências. Trabalho de Conclusão de Curso (Graduação) - Universidade Federal do Rio de Janeiro, Escola Politécnica. Rio de Janeiro, RJ, Brasil. 2017.

MAGALHÃES, E. F. Fissuras em alvenarias: Configurações típicas e levantamento de incidências no estado do Rio Grande do Sul. Dissertação (Mestrado) - Universidade Federal do Rio Grande do Sul. Porto Alegre, RS, Brasil. 2004.

PIRES, P F. Estudo da carbonatação avançada em concretos contendo adições minerais. Dissertação (Mestrado) Universidade Federal de Goiás. Goiânia, GO, Brasil. 2016.

RESENDE, P. B., et al. Fissuras causadas por movimentações térmicas no concreto. XIII Semana Universitária. XII Encontro de Iniciação Científica. V Feira de Ciência, Tecnologia e Inovação. UNIFIMES. Mineiros, GO, Brasil. 2018.

VIEIRA, T. L. Fissuras em concreto: estudos de caso em Florianópolis. Trabalho de Conclusão de Curso (Graduação) - Universidade Federal de Santa Catarina. Florianópolis, SC, Brasil. 2017.

ZUCHETTI, P. A. B. Patologias da construção civil: Investigação patológica em edifício corporativo de administração pública no vale do Taquari/RS. Trabalho de Conclusão de Curso (Graduação) - Centro Universitário Univates, Centro de Ciências Exatas e Tecnológicas. Lajeado, RS, Brasil, 2015.

ZUCCHI, F. L. Técnicas para o reforço de elementos estruturais. Trabalho de Conclusão de Curso (Graduação) Universidade Federal de Santa Maria. Centro de Tecnologia. Santa Maria, RS, Brasil. 2015. 